\title{
Dilemas e Desafios na Formação do Profissional em Saúde Coletiva: O Caso da Faculdade de Saúde Pública
}

\section{Cleide Lavieri Martins*}

A Faculdade de Saúde Pública/USP (FSP) está comemorando 70 anos de existência. Nesses anos vem enfrentando dilemas e desafios relacionados com a formação de profissionais em saúde pública.

Gostaria de contribuir com a reflexão de hoje, trazendo algumas questões que vêm sendo discutidas neste momento na FSP, em mais um processo de reformulação do Curso de Especialização em Saúde Pública.

O Curso está aberto a profissionais de nível superior e geralmente é procurado por pessoas com projetos individuais de formação, em sua maioria já inseridas no mercado de trabalho e que enfrentam dificuldades em conciliar trabalho e estudo. Não se observa que a opção pela Especialização faça parte de um projeto institucional de desenvolvimento de pessoal dos serviços de origem dos alunos.

A composição do grupo de alunos segundo formação básica vem mudando nos últimos anos. Vasconcellos \& Narvai $^{(2)}$ mostram que em $1985,42,5 \%$ dos alunos eram médicos, e em 1994 esse percentual baixou para 9,6\%; em contrapartida 3,9\% eram assistentes sociais, em 1985, e em 1994 esse percentual subiu para $21,2 \%$. O conjunto de alunos com profissões que tradicionalmente são esperadas nesse tipo de Curso (medicina, enfermagem, odontologia, veterinária e farmácia-bioquímica) foi de $81,1 \%$ em 1985 , e $37,5 \%$ em 1994 . Essa nova composição é provavelmente reflexo de mudanças no mercado de trabalho: alterações em planos de cargos e carreiras (suprimindo ou criando carreiras), ampliação do quadro de pessoal ou aumento da oferta de emprego para determinadas categorias profissionais.

\footnotetext{
* Assistente do Departamento de Prática de Saúde Pública da Faculdade de Saúde Pública da USP
} 
Levantamento realizado, em setembro de 1994, nas 266 fichas de inscrição dos candidatos ao Curso de 1995, onde os mesmos responderam à questão: "Por que você deseja fazer este Curso?" - permitiu, apesar das limitações desse tipo de levantamento, agrupar as expectativas dos candidatos em relação ao Curso, em três tipos:

- capacitação para aplicação imediata - grupo formado por indivíduos que já atuam no setor saúde e que estão buscando:

- reflexão e análise crítica sobre sua prática profissional;

- capacitação para exercer funções administrativas no setor saúde; ou

- aprofundamento em determinado tema ou área da saúde pública (saúde materno-infantil, saúde do trabalhador, vigilância sanitária, epidemiologia, etc.),

- desenvolvimento pessoal - grupo formado por pessoas que já estão trabalhando ou que desejam se inserir no setor saúde e esperam:

- obter uma nova profissão (área de educação em saúde pública);

- ampliar opções de emprego;.

- mudar a área de atuação;

- "melhorar currículo", " dar continuidade aos estudos" ; ou

- "atualizar-se na área de saúde pública"

- interdisciplinaridade - grupo formado por indivíduos que não atuam diretamente no setor saúde e não pretendem ser profissionais de saúde, mas que têm interesse em conhecer a temática de saúde pública (exemplo: saúde $\mathrm{x}$ meio ambiente).

Como indicado, as expectativas são bastante diversas: atualização, aprofundamento, formação, sendo portanto muito difícil atendê-las com uma única modalidade e nível de curso. Neste contexto a busca da formação do "sanitarista generalista", eixo do Curso, têm sido constante e intensamente questionada.

O Curso ministrado tem longa duração ( 820 horas), atividades presenciais, basicamente com aulas expositivas, é centrado no professor e com estrutura seqüencial numa concepção de que a teoria antecede à prática, reforçando a dicotomia entre reflexão e ação, empírico e teórico.

Diante do exposto diferentes possibilidades se apresentam. Uma delas é o caminhar para proporcionar múltiplas respostas. Nesse sentido o processo de reformulação do Curso de Especialização em Saúde Pública, aponta para uma tendência de oferta de novos cursos, atendendo às diversas demandas sociais de formação/capacitação em Saúde Pública, incorporando, na medida do possível, tecnologias inovadoras de ensino/aprendizagem e outras modalidades de curso como por exemplo: semi-presencial e ensino à distância. Na própria FSP tem-se observado aumento de oferta de cursos nas modalidades de aperfeiçoamento, atualização e especialização de curta duração, com demanda crescente 
de alunos. Outra tendência observada é a de reformular, o atual curso, mas ainda na proposta de formação generalista.

Essas questões expressam distintas concepções de educação. Um dos caminhos encontra-se na perspectiva da "educação permanente em saúde". Nesse sentido, a FSP está implantando o Centro de Educação Permanente em Saúde Pública (CEP/FSP) procurando fortalecer as diversas atividades que envolvem a formação de profissionais de saúde pública. Como estratégia inicial, optouse por realizar em janeiro 1995 uma Oficina de Trabalho. Nessa ocasião, o grupo de docentes participantes conceituou educação permanente como "um processo educacional individual, grupal ou coletivo que, partindo das práticas de trabalho das instituições envolvidas, busca contribuir para sua transformação com vistas não apenas a responder mas também antecipar-se às necessidades e demandas em saúde da sociedade, com a seguintes características: garantir compromisso formal das instituições participantes no sentido de implementar um projeto de interação permanente no processo de promoção de saúde; estar centrado na prática institucional e, por meio da observação e detecção de problemas, promover um processo educacional de ampla reflexão teórico-prática que permita elaborar estratégias de intervenção a curto, médio e longo prazos considerando a incorporação de tecnologias inovadoras de ensino"(1).

A FSP vem portanto passando por um momento rico e interessante, cujos desdobramentos merecem ser observados e acompanhados.

\section{Referências Bibliográficas}

1. UNIVERSIDADE DE SÃO PAULO. Faculdade de Saúde Pública. Centro de Educação Permanente em Saúde Pública. Relatório da I Oficina Pedagógica: Educação Permanente em Saúde. São Paulo, 1995.

2. VASCONCELLOS, M. P. C. \& NARVAI, P. C. Algumas características dos alunos do Curso de Especialização em Saúde Pública da USP no período de 1985-94. In: UNIVERSIDADE DE SÃO PAULO. Faculdade de Saúde Pública. Reflexões sobre revisão institucional curricular. São Paulo, 1994. 